\title{
Study on the Multi-Level Growth System of Xi'an
}

\author{
Tian $\mathrm{Na}$ \\ College of Economics and Management, Xi'an University
}

Keywords: Xi'an; economy; multi-level economic growth system

\begin{abstract}
Under the context of multi-level growth and development, how economy of Xi'an should continue to innovate and develop has become the focus of all circles in Shaanxi society. Based on the theoretical basis of the development of the multi-level economic growth system, this paper makes a contrastive analysis of the current situation, advantages and disadvantages of the development of the multi-level economic growth system in Xi'an, and probes into the problems and the restricting factors of the development of the multi-level economy in Xi'an. Through the analysis and comparison of economic development in Xi'an, this paper puts forward the basic ideas and countermeasures of the development of the multi-level economic growth system in Xi'an.
\end{abstract}

\section{The Present Situation of the Multi-Level Growth System in Xi'an.}

At this moment, the economic model of Xi'an is based on scientific and technological resources, and has established an innovative mode of combining "knowledge-technology-industry" with market-oriented, enterprise-oriented, production-oriented and industry-oriented, the innovation and development of the multi-level growth system of urban economy is guided by the system of technological innovation. As the country launched the development strategy of the China Western Development, Xi'an then put forward the new orientation of the new starting point of innovation development from four aspects: international, market, humanism and ecology -- the Western economic strong city which combines the history of Xi'an with modern culture. Urban Development should be based on resources,and form the carrier of the development of the multi-level growth system of the urban economy of the product, enterprise and industry. In the present situation, how Xi'an has grasped this period of strategic opportunity has become a subject of great concern in the context of building a harmonious society and scientific outlook on development In this paper, the problems and constraints in the development of the multi-level economic growth system in Xi'an are analyzed through the analysis of the current economic development in Xi'an, this paper puts forward the framework and solution of the development of the multi-level economic growth system in Xi'an. According to the comparative advantage of the development of the multi-level growth system of Xi'an Economy, the focus of economic development should be determined, and the economic development talents should be retained; To formulate and implement preferential policies to encourage the development of a foreign-owned economy.

One of the factors of economic growth in Xi'an is that it is the ancient city with a long history and the Western mega-city which is a famous historical and cultural city first announced by the State Council. In recent years, as a comprehensive indicator of regional economic conditions GDP shows that the total volume of economy in Xi'an has not increased much, which shows that the scale and growth rate of the total economy have not been significantly improved. This is mainly manifested in the following aspects:

The small amount of industrial economy is one of the main reasons for the low GDP of Xi'an.

From the point of view of the industrial context, the main reason for the low number and low benefits of industrial enterprises is to maintain the balance of nature, Xi'an uses energy superiority to promote urban development is the key of its economic development strategy.

We should take active actions to promote the development of the commercial base of the frontier cities in northwest China and the neighboring countries, so as to improve traffic, communication and market facilities, we need to push forward the strategy of developing the cities along the frontier 
The enhancement of the sustainable development capacity of Xi'an and the creation of a cultural image of the city need to continue to be strengthened in the development of high-tech and higher education. Of course, to improve the regional science, technology and culture and the competitiveness of cities also needs to be in the cultivation and attracting talent and so on. Since 2010, Xi'an has been planning the construction of a 10-square-kilometer "special area for the reform of science and Technology Resources. the development of multi-level economic growth system is supported by strengthening the platform of "spillover effect" of scientific and technological innovation. As the first productive force, technology is a prerequisite for the development of the multi-level growth system of urban economy. The integration of resources and economy is an important engine to promote the development of the multi-level growth system of urban economy. The types of cities that take resource advantage as the dominant innovation development can be divided into resource-based cities, cultural cities and start-up cities which require us to analyze the types of urban dominant resources. Most of the existing research on the restriction and effect of Urban Development rests on the study of natural resources, tourism resources and so on. Few of them analyze the development path of science and technology resource-based Cities. Therefore ,in order to achieve multi-level economic growth in $\mathrm{Xi}$ 'an, the upgrading and transformation of traditional industries should be accelerated, with a focus on the development of the high tech sector and the acceleration of the development of the Industrial Economy of the project

\section{An Analysis of the Advantages and Disadvantages of the Development of Multi-Level Economic Growth System in Xi'an.}

The following is a comparison of the advantages and disadvantages of the current state of economic multilevel growth in Xi'an.

\section{Comparative Advantage}

Abundant human resources. Talent is a prerequisite for a wide range of large multinational companies, as well as R \& D At present, Xi'an has nearly 100 national key laboratories, dozens of universities, thousands of scientific research institutes, nearly one million university students, and the fourth highest ranking in the country in terms of scientific and technological strength and Research and development capacity, the power of innovation can be seen to be very strong. By 2009, technological advances had contributed more than 50 per cent to the multi-level growth system of the Xi'an economy. Among them, the Xi'an International Studies University has trained a large number of high-level foreign language talents in business. It can be seen that the rich resources of higher talents provide strong intellectual support and human resource protection for the economic development of Xi'an, the provincial capital.

A good image of the city. Xi'an is an ancient city with a long history, deep cultural background and great international influence. The city scenery and humanistic environment as well as the urban landscape and construction are more outstanding. At the same time, the information service in Xi'an is fast and convenient, the system of laws and regulations is relatively perfect, the administration is efficient and clean, and the business environment is open and fair. These favorable conditions and factors can attract all kinds of enterprises to take root and develop here, this beautiful living environment to attract enterprises in this development has added a code of weight.

It's got a lot of money. The economic development environment of Xi'an has brought huge government resources and information resources through its convenient position as the political center of Shaanxi Province, which has a large number of regional government organs. As the economic center of the province, Xi'an has a very rich resource and industrial base. The economic growth in Xi'an is becoming more and more obvious, which is closely related to its status as an important industrial base in the country and a key city open to the outside world in the central and western regions. At this point, the economic development of Xi'an has climbed to the fast-growing platform and has entered a new round of rapid economic growth stage.

Location and geographical advantage of transportation hub. As the center of the northwest region with the most preferential policies and inputs from the state in support of the development of the western region, as well as the economic, financial transportation and information centers in the 
northwest, Xi'an can be the foundation and carrier of the development of the western region, so as to play a variety of service functions. Therefore, Xi'an has sufficient conditions in the regional layout to become the key "forerunner" of the great development, and it has the condition to become the "first step" in the development project.

Introduction of foreign banks. The introduction of foreign banks is one of the important forces in the development of the multi-level growth system of Xi'an economy. The world's top 500 international financial giants, such as standard chartered and HSBC, which have a high international profile and a strong sense of service, are already operating in the country, where they have updated the definition of the financial sector, and with the Local Bank of Xi'an to develop together.

\section{Comparative Disadvantage}

Lack of economic strength. Xi'an is located inland, not on the river, not in the river, not by sea, without sea, only through railways and highways with low cargo capacity and high transport costs. The small size of the economy has led to lower levels of GDP per capita in Xi'an compared with the national level. The size of the Xi'an economy doesn't seem to have much of an advantage in attracting large companies to take root here.

Low level of financial services. Large enterprises tend to take root in a place where they have a convenient and rapid advantage in terms of financial service levels. Compared with cities such as Beijing, Shanghai and Guangzhou, the credit volume of Xi'an is small, the credit is scattered, the credit demand is concentrated, the financing channel is single, and the contradiction between the lack of matching with the administrative resources and so on confirms the Poor Financial Service Level in Xi'an.

The shortage of high-end talents and the serious brain drain. The development of a multi-level growth economy requires first and foremost a large number of high-level expertise. At this moment, however, there is still a phenomenon in the introduction of "hard to introduce and easy to lose": talented people such as the various registrars who have obtained recognized professional qualifications, the high-level management of international practices and rules of the World Trade Organization, finance, insurance personnel, scientific and technical personnel with a certain capacity for product development and scientific and technological personnel capable of carrying out major scientific and research activities independently. On the whole, the problem of the unreasonable distribution structure of the industry in Xi'an is quite salient: a large number of enterprises need to flow to the south-east coastal economic developed areas, there is a large pool of talent in Xi'an, but there is a lack of high-level talent.

\section{Countermeasures for the Development of a Multi-Level Economic Growth System in Xi'an.}

From the analysis of the advantages and disadvantages above, it can be seen that the development of the multi-level growth system of the Xi'an economy has certain comparative advantages and conditions, but there are also many relative disadvantages and gaps. We can only combine the actual situation in Xi'an, look for your own development patterns and paths. The following responses and recommendations are made in response to this argument:

To determine the focus of the multi-level economic growth system in $\mathrm{Xi}^{\prime}$ an according to the Comparative Advantage of Xi'an Economy

Building on the development of the multi-level economic growth system in Xi'an, and establishing the objective to create the most suitable economic development environment in the western region, to develop the high-tech industry, to accelerate the development of tertiary sector of the economy, and to work to improve the multi-level economic growth system in Xi'an, focusing. on attracting multinational enterprises and large domestic enterprises to come to Xi'an for the scale of the root-up and establishment of various functional enterprise bases, in order to enhance the city's comprehensive service function and to build the best environment suitable for economy and life to blend with each other as the support point, attracting large-scale private .enterprises in the industry and abroad to settle in Xi'an, we should adhere to the integration of local training and introduction, and develop the economic multi-level growth system such as economy and industrial project economy 


\section{Retain the talent needed for the development of the multi-level growth}

System of the economy

Human resource is the essential condition to activate the elements of Xi'an economy and to make the "low-cost expansion" of the domestic market of foreign capital. And retaining talent is one of the first conditions to compete with other cities for foreign investment, which will be a win-win outcome for both Xi'an and foreign investment. However, the problem of brain drain is the biggest problem in Xi'an at present. According to the low-lying effect, good environment and condition is the necessary condition to bring in and keep the talented person and to make the matching. We will make Xi'an the three major centers of information, talent gathering and talent allocation as soon as possible, bring in the shortage of talents and train high-level talents and build up the human resource reserve, so as to lay a solid foundation for the environment of the multi-level economic growth system in Xi'an.

Formulate and implement a policy of facilitating the development of the multi-level economic growth system in Xi'an

A policy of direct incentives for the relocation of Enterprise Group Headquarters to Xi'an, through the establishment of special funds for economic development. At the same time, we should pay attention to the continuity and stability of the policy, and implement the financial reward according to the increase of the enterprise's contribution to the local finance, so as to enhance the enterprise's confidence in the landing of Xi'an. On the basis of the preferential policy of attracting investment in Xi'an Economic Development Zone, the tax revenue will be relaxed appropriately. To the introduction of business leaders, employees and their children in the areas of household registration, employment, school, etc. For enterprises that are industry-oriented, appropriate subsidies are granted in accordance with their ability to contribute to local finance.

\section{Ways to Promote the Development of the Multi-Level Economic Growth System in Xi'an}

The Path to the development of multi-level economic growth system in Xi'an follows the relevant economic development patterns in the following ways:

1. To promote the development of the multi-level economic growth system in Xi'an through the structural optimization and upgrading to rely on the first, second and third industries for harmonious and common development;

2. The basic elements of economic development depend on human resources, science and technology as well as innovative management mode to promote the development of the multi-level Economic Growth System in Xi'an;

3. To promote the development of the multi-level economic growth system in accordance with the law and characteristics of economic and cultural integration and development, and transform the cultural market of Xi'an into a strong cultural market;

4. To promote the development of the multi-level economic growth system in Xi'an, we need to pull the transition from pulling the economy to relying on the coordination of consumption, investment and exports.

\section{Concluding remarks}

In conclusion, to accelerate the development of the multi-level economic growth system in Xi'an, we need to adopt the system innovation, the platform to build, through the attraction of foreign capital, the introduction of a large number of high-end talents and the integration of government policies with the market, to provide the development path for the multi-polar economic growth of science and technology resource-based cities' The economic mode of Xi'an, which integrates science and technology with economic development through policy, environment and available scientific and technological resources, promotes the development of Xi'an as an innovation city of science and technology resources, thus, the system of multi-level economic growth in Xi'an has been improved. 


\section{Acknowledgement}

Fund Project: Social Science Planning Fund for Xi'an 2018(18ZT11)

\section{References}

[1] $\mathrm{Wu}$ Xiaojing. Changsha challenges the economy at headquarters. High Technology and industrialization, 2004(10).

[2] Qu Zengmin. The development of Xi'an [m]. Xi'an: Shaanxi People's Publishing House,2000.

[3] Jiang Shiyin. Study on adjustment of regional industrial structure and choice of leading industry [ $\mathrm{m}]$. Shanghai People's Publishing House.

[4] Joseph Schumpeter. Theory of Economic Development [m]. Commercial Press, 1988.

[5] Wu Haihua. Modern Economic Development [m]. Qingdao Press, 1995.

[6] H.Gennari. A comparative analysis of Industrialization and Economic Growth [m]. Shanghai Sanlian Publishing House, 1993.

[7] Xi'an Statistical Yearbook (2004) [m]. BEIJING: China Statistics Publishing House,2004.

[8] Chengdu Statistical Yearbook (2004) [m]. BEIJING: China Statistics Publishing House,2004.

[9] Zhou Shuqin. Sixty years of urbanization in China: process, characteristics and prospects [J]. China's most famous city, 2009(10):19-25.

[10] Pan Xiaodong. A study on the Road Map of low-carbon urban development in China [J]. China's population resources and environment, 2010,20(10)13-18

[11] Qian wei. Innovative Urban Development Path_-The experience and enlightenment of American Typical Urban Transformation [j]. Reform and opening, 2011(2): 16-19. 